\title{
Prenatal vitamin D status and offspring's growth, adiposity and metabolic health: a systematic review and meta-analysis
}

\author{
Christina Santamaria ${ }^{1}$, Wei Guang $\mathrm{Bi}^{1}$, Line Leduc ${ }^{1,2}$, Negar Tabatabaei ${ }^{1,3}$, Prévost Jantchou ${ }^{1,4}$, \\ Zhong-Cheng Luo ${ }^{1}$, François Audibert ${ }^{1,2}$, Anne Monique Nuyt ${ }^{1,4}$ and Shu Qin Wei ${ }^{1,2 *}$ \\ ${ }^{1}$ Centre hospitalier universitaire Sainte-Justine Research Center, Montreal, QC H3T 1C5, Canada \\ ${ }^{2}$ Department of Obstetrics and Gynecology, University of Montreal, Montreal, QC H3T 1C5, Canada \\ ${ }^{3}$ Department of Obstetrics and Gynecology, University of Sherbrooke, Sherbrooke, QC J1H 5N4, Canada \\ ${ }^{4}$ Department of Pediatrics, Faculty of Medicine, University of Montreal, Montreal, QC H3T 1C5, Canada
}

(Submitted 20 July 2017 - Final revision received 8 November 2017 - Accepted 3 December 2017 - First published online 11 January 2018)

\section{Abstract}

In this systematic review and meta-analysis of observational studies, we aimed to estimate the associations between prenatal vitamin $\mathrm{D}$ status and offspring growth, adiposity and metabolic health. We searched the literature in human studies on prenatal vitamin D status and offspring growth in PubMed, up to July 2017. Studies were selected according to their methodological quality and outcomes of interest (anthropometry, fat mass and diabetes in offspring). The inverse variance method was used to calculate the pooled mean difference (MD) with $95 \% \mathrm{CI}$ for continuous outcomes, and the Mantel-Haenszel method was used to calculate the pooled OR with 95\% CI for dichotomous outcomes. In all, thirty observational studies involving 35032 mother-offspring pairs were included. Vitamin D status was evaluated by circulating 25-hydroxyvitamin D (25(OH)D) level. Low vitamin D status was based on each study's cut-off for low 25(OH)D levels. Low prenatal vitamin D levels were associated with lower birth weight (g) (MD -100.69; $95 \%$ CI -162.25, -39.13), increased risk of small-for-gestational-age (OR 1.55; $95 \%$ CI 1.16, 2.07) and an elevated weight (g) in infant at the age of 9 months (g) (MD 119.75; 95\% CI 32.97, 206.52). No associations were observed between prenatal vitamin D status and other growth parameters at birth, age 1 year, 4-6 years or 9 years, nor with diabetes type 1. Prenatal vitamin D may play a role in infant adiposity and accelerated postnatal growth. The effects of prenatal vitamin D on long-term metabolic health outcomes in children warrant future studies.

Key words: 25-Hydrovitamin D: Pregnancy: Infant growth: Adiposity: Metabolic health

Barker's hypothesis ${ }^{(1)}$ about fetal programming stating that adult diseases are partly attributable to insufficient intra-uterine nutrition is now well accepted ${ }^{(2)}$. Nutrient deficiencies during pregnancy can induce changes in this critical period that will affect physiology and body composition in both fetal and postnatal development ${ }^{(2)}$. Among those changes, one of the most widely reported is suboptimal infant growth ${ }^{(2)}$. A common problem with lower birth weight or being born smallfor-gestational-age (SGA) is the catch-up growth that follows in early childhood ${ }^{(3)}$. Indeed, children recover their normal fat mass before they recover their normal height, which can lead to elevated adiposity and hormonal dysregulations that can induce metabolic health problems ${ }^{(3)}$. Therefore, child growth, adiposity and metabolic health may be partly determined by prenatal nutritional status.

One nutrient of emerging interest is vitamin $\mathrm{D}$, the deficiency of which is a nutritional issue extremely widespread around the globe ${ }^{(4)}$. There is no universally accepted definition of vitamin D deficiency. On the basis of circulating 25-hydroxyvitamin D (25(OH)D) concentration, different cut-offs have been used to define vitamin D status. The Institute of Medicine states that a serum $25(\mathrm{OH}) \mathrm{D}$ concentration $<30 \mathrm{nmol} / 1$ is vitamin D deficiency ${ }^{(5)}$, whereas the Endocrine Society defines vitamin D deficiency as $25(\mathrm{OH}) \mathrm{D}<50 \mathrm{nmol} / \mathrm{l}^{(6)}$. Vitamin D can be absorbed through alimentation or synthetised in the skin with sun exposure ${ }^{(7)}$. As cutaneous synthesis under sunlight is responsible for the majority of vitamin D in circulation ${ }^{(8)}$, the problem is alarming in Canada where almost a third of the population had plasma concentrations of $25(\mathrm{OH}) \mathrm{D}<50 \mathrm{nmol} / \mathrm{l}^{(9)}$. Vitamin D deficiency is common during pregnancy; almost $40 \%$ of pregnant women had plasma $25(\mathrm{OH}) \mathrm{D}$ concentrations $<50 \mathrm{nmol} / 1$ in a prospective multi-centre cohort study in Canada ${ }^{(10)}$, and it represents a common public health problem ${ }^{(11)}$.

As vitamin $\mathrm{D}$ has an important role in placental metabolism $^{(12)}$ and metabolic health during pregnancy ${ }^{(13)}$, our hypothesis is that low prenatal vitamin D status has an effect on

Abbreviations: 25(OH)D, 25-hydroxyvitamin D; MD, mean difference; SGA, small-for-gestational-age.

* Corresponding author: S. Q. Wei, Assistant Professor, email shu.qin.wei@umontreal.ca 
infant growth, adiposity and metabolic health. As child growth and metabolic health are important for childhood well-being and long-term health outcomes, this systematic review and meta-analysis aimed to better understand the role of prenatal vitamin D status in child growth, adiposity and metabolic health.

\section{Methods \\ Electronic literature search}

To evaluate the overall effects of prenatal vitamin D status on child's growth, adiposity and related metabolic disorders, literature searches on prenatal vitamin D status and newborn anthropometry, SGA, child's growth and metabolic health disorders were conducted on electronic databases of the human literature in PubMed, up to July 2017 using 'vitamin D' and 'pregnancy' as keywords. All 2550 studies have been screened by their title and abstract and initially selected if they reported an association between prenatal vitamin D status and newborn anthropometry, more specifically birth weight, length, head circumference and SGA, as well as child's growth, adiposity and metabolic health, more specifically child weight, length, BMI, fat mass or diabetes type 1. Additional articles have been searched through reviewing the reference lists of relevant articles. Only articles in English have been considered. When only the abstract was available, the author was contacted to provide the data.

\section{Selection of studies}

After screening the titles and abstracts, sixty articles were fully read. Twenty-three of them were excluded because they met at least one exclusion criterion: (a) they were reviews, case reports or comments; (b) maternal vitamin D levels were estimated according to their nutrient intake; or (c) the data are incomplete or impossible to merge with other studies. Of the remaining thirty-seven studies, seven were further excluded because they did not meet all the inclusion criteria. The inclusion criteria were as follows: (a) study design was a prospective or retrospective cohort study; (b) there were data on child growth, adiposity or metabolic health, such as weight, length, BMI, head circumstance, SGA, skinfold thickness, fat mass (g or \%) and diabetes type 1 ; (c) study population was pregnant women without pre-existing chronic disease; (d) vitamin D status was indicated by $25(\mathrm{OH}) \mathrm{D}$ assays in maternal or cord blood samples taken before or at delivery; and (e) the study met the predefined methodological quality assessment criteria for nonrandomised observational studies ${ }^{(14)}$. When data were incomplete, authors were contacted and asked to provide the needed data. Crozier et $a l^{(15)}$, Gale et $a l^{(16)}$, Josefson et $a l^{(17)}$ and Leffelaar et $a l .{ }^{(18)}$ provided us with additional useful data.

Two reviewers (C. S. and W. G. B.) independently searched the electronic literature, screened titles and abstracts and read full-length articles in order to make final inclusion or exclusion decisions. The most complete version of an article was selected when there were two different publications from the same study. Any disagreements were resolved by discussion with a third reviewer (S. Q. W.).
We evaluated the methodological quality of each study using Newcastle-Ottawa Scale (NOS) ${ }^{(14)}$. The NOS is a method recommended by the Cochrane Non-Randomized Studies Methods Working Group to evaluate the quality of the study. Points are assigned based on the selection process of cohorts ( $0-4$ points), the comparability of the cohorts ( $0-2$ points) and the identification of the exposures and the outcomes of research participants ( $0-3$ points). A score of at least 7 out of 9 was defined as high quality.

\section{Data collection and analysis}

The primary exposure variable was vitamin D deficiency. The dependent variables were offspring growth and adiposity outcomes. Some outcomes were continuous variables, such as birth weight, birth length, head circumference, BMI and fat mass, and other outcomes were dichotomous variables, such as SGA and diabetes type 1 . To merge the results from various studies in meta-analysis, we constructed two-by-two tables of prenatal vitamin D status $v$. the presence or absence of adverse offspring outcomes for dichotomous outcomes. For continuous outcomes, the mean values and standard deviations and number of subjects were extracted based on prenatal vitamin D status.

No universal consensus exists in the scientific community concerning the definition of vitamin D deficiency. When different cut-offs were presented in a study, we decided to use the lowest cut-off point as we were interested in studying the effects of vitamin D deficiency. In this meta-analysis, for any outcome with different cut-offs, subgroup analysis was performed. All individual studies reporting the same outcome were pooled to calculate the overall effect.

To merge data for continuous outcomes, the mean values and standard deviations and the number of subjects were needed from each group (vitamin D deficiency and vitamin D non-deficiency) in each study. The mean difference (MD) was calculated using the inverse variance method. To merge dichotomous outcomes, the number of patients with the outcome (SGA and diabetes type 1) and the total in each group (vitamin $\mathrm{D}$ deficiency $v$. vitamin $\mathrm{D}$ non-deficiency) were needed. The Mantel-Haenszel method was then used to present the effect as OR and 95\% CI. For both continuous and dichotomous outcomes, when the heterogeneity was significant, defined as $I^{2}$ of $>50 \%$, the analysis model was changed from fixed effect to random effects. Forest plots were used to illustrate the point estimate with 95\% CI. Data meta-analysis was performed using the Review Manager (RevMan) $5.3^{(19)}$

Two independent reviewers (C. S., W. G. B.) went through the process of data extraction and calculation. We followed the Meta-Analysis of Observational Studies in Epidemiology (MOOSE) guidelines ${ }^{(20)}$.

\section{Results}

In all, thirty studies involving a total of 35032 mother-offspring pairs were included in this meta-analysis. Among the sixty preselected articles, twenty-three were excluded because they had insufficient data. Then, seven of the remaining thirty-seven 


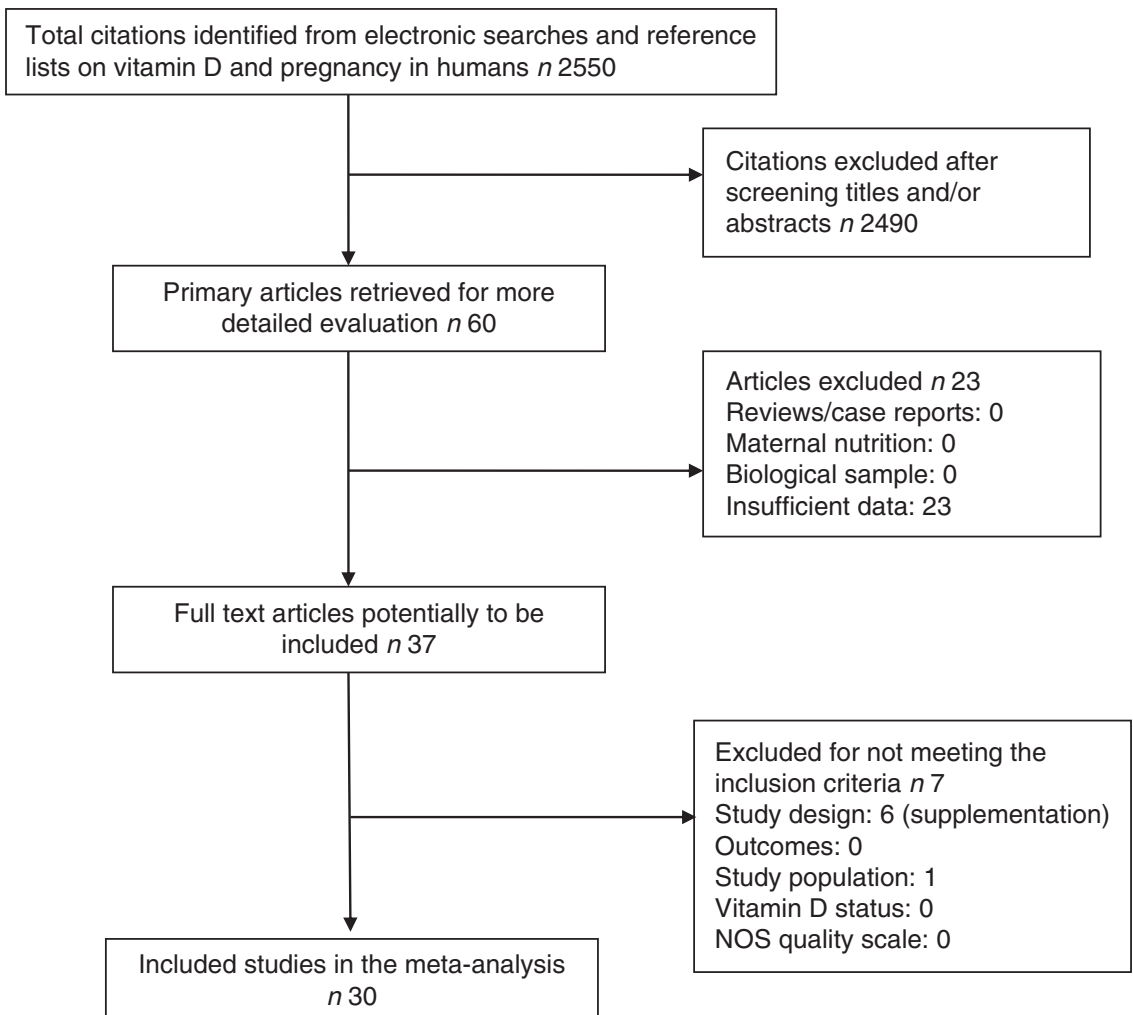

Fig. 1. Flow chart of study selection process in a systematic review. NOS, Newcastle-Ottawa Scale.

articles were excluded because they did not meet all inclusion criteria: six of them were not observational studies as they used supplementation $^{(21-26)}$ and one of them had a population of pregnant women with a chronic disease - diabetes type $2^{(27)}$. The details of the process of literature search and selection of studies are presented in Fig. 1 - study eligibility flow chart. Table 1 shows characteristics of the included studies: study design, study setting (country), sample size, gestational age when the blood sample was taken, season when the blood sample was taken (percentage of winter), assay method used to determine the $25(\mathrm{OH}) \mathrm{D}$ level (including chemiluminescent immunometric assay, electrochemiluminescence immunoassay, ELISA, liquid chromatography-tandem MS, RIA and HPLC), $25(\mathrm{OH}) \mathrm{D}$ cut-off the authors used (when there were more than one, the lowest one was chosen) and child outcomes. Four studies $^{(17,35,43,51)}$ measured cord blood $25(\mathrm{OH}) \mathrm{D}$ levels and the remaining studies measured maternal blood 25(OH)D levels. Cord blood vitamin D levels were lower than maternal blood levels, but they were highly correlated ${ }^{(54)}$. We also performed sensitivity analysis (excluding the studies with only cord blood data) and similar results were obtained. There was no evidence of publication bias.

Among the finally selected thirty articles, sixteen studies $^{(16-18,28,30,32,33,35,36,44-46,49,51-53)}$ involving 18096 participants reported birth weight. Vitamin D deficiency definition was different in individual studies. We used a $25(\mathrm{OH}) \mathrm{D}$ cut-off of $25 \mathrm{nmol} / 1$ in seven studies ${ }^{(28,30,32,33,35,46,49)}$, a cut-off of $27.5 \mathrm{nmol} / 1$ in one study ${ }^{(51)}$, a cut-off of $28 \mathrm{nmol} / 1$ in one study $^{(44)}$, a cut-off of $30 \mathrm{nmol} / 1$ in three studies $^{(16,18,36)}$ and a cut-off of $50 \mathrm{nmol} / 1$ in four studies ${ }^{(17,45,52,53)}$. Fig. 2 shows the summary $\mathrm{MD}$ of the association between low prenatal $25(\mathrm{OH}) \mathrm{D}$ levels and birth weight. The overall summary MD of birth weight (g) was -100.69 (95\% CI $-162 \cdot 25,-39 \cdot 13)$ $(P=0.001)$. There was significant heterogeneity across studies ( $\left.\tau^{2}=12358.50 ; \chi^{2}=180.67 ; \quad I^{2}=92 \% ; P<0.00001\right)$. Subgroup analysis (online Supplementary Fig. S1) shows a significant association between prenatal $25(\mathrm{OH}) \mathrm{D}<30 \mathrm{nmol} / 1$ and a lower birth weight (MD -111.26; 95\% CI -139.60, -82.92; $P<0 \cdot 00001)$. There was no significant heterogeneity. Subgroup analysis also shows significant association between prenatal $25(\mathrm{OH}) \mathrm{D}<25 \mathrm{nmol} / 1$ and a lower birth weight (g) (MD 212.43; $95 \%$ CI $-408 \cdot 90,-15 \cdot 96 ; P=0.03$ ), but this association would become non-significant if accounting for multiple tests. Heterogeneity was significant.

In all, ten studies $(16,17,35,36,44-46,49,51,53)$ involving 8191 mother-newborn pairs reported the relationship between prenatal vitamin D and newborn length/height. As some studies had data on the length at $\operatorname{birth}^{(16,17,36,44-46,49,53)}$ while others had data on the length at approximately 2 weeks after birth $^{(35,51)}$, the outcome of interest is newborn (0-28d) length instead of birth length. There was no association between prenatal vitamin D status and newborn length (MD -0.00; $95 \%$ CI $-0.32,0.31 ; P=0.98)$. There was significant heterogeneity $\left(\tau^{2}=0.18 ; \chi^{2}=48.89 ; I^{2}=82 \% ; P<0.00001\right)$.

Seven studies ${ }^{(16,35,36,44,46,49,51)}$ on newborn head circumference involving 5018 participants were included in this meta-analysis (vitamin D deficiency cut-off of $30 \mathrm{nmol} / \mathrm{l}^{(16,36)}, 28 \mathrm{nmol} / \mathrm{l}^{(44)}$, $27.5 \mathrm{nmol} / \mathrm{l}^{(51)}$ or $\left.25 \mathrm{nmol} / \mathrm{l}^{(35,46,49)}\right)$. No association between 
Nesitish Journal of Nutrition

Table 1. Characteristics of the included studies

\begin{tabular}{|c|c|c|c|c|c|c|c|c|}
\hline Studies & Country & Study design & Sample size $(n)$ & $\begin{array}{l}\text { Specimen GA } \\
\text { (weeks) }\end{array}$ & Season & $\begin{array}{l}\text { Assay } \\
\text { method }\end{array}$ & $\begin{array}{l}25(\mathrm{OH}) \mathrm{D} \text { cut- } \\
\text { off (nmol/l) }\end{array}$ & Child outcomes \\
\hline Ates et al. ${ }^{(28)}$ & Turkey & Prospective cohort & 229 & $13 \cdot 2(11.0-14 \cdot 0)$ & $51 \cdot 1$ & LC-MS & $<25 v \cdot \geq 25$ & $\begin{array}{l}\text { SGA } \\
\text { Birth weight }\end{array}$ \\
\hline Bodnar et al. ${ }^{(29)}$ & USA & Prospective cohort & 412 & $<22.0$ & 21.1 & ELISA & $<37,5 v_{.} \geq 37,5$ & SGA \\
\hline Bowyer et al. & Australia & Prospective cohort & 971 & $30 \cdot 0-32 \cdot 0$ & NA & CLIA & $<25$ v. $\geq 25$ & Birth weight \\
\hline Boyle et al. & New Zealand & Prospective cohort & 1710 & $15 \cdot 0$ & NA & LC-MS & $<25$ v. $\geq 25$ & SGA \\
\hline Burris et al. ${ }^{\left({ }^{2}\right)}$ & USA & Prospective cohort & 1133 & $26 \cdot 0-28 \cdot 0$ & NA & $\begin{array}{l}\text { CLIA } \\
\text { RIA }\end{array}$ & $<25 v . \geq 25$ & $\begin{array}{l}\text { SGA } \\
\text { Birth weight }\end{array}$ \\
\hline Chen et al. ${ }^{(33)}$ & China & Prospective cohort & 3658 & $\begin{array}{r}<13(35.1 \%) \\
13-27(62.0 \%) \\
>28(2.90 \%)\end{array}$ & $20 \cdot 2$ & RIA & $\begin{array}{l}<25 v . \geq 25 \\
<50 v . \geq 50\end{array}$ & $\begin{array}{l}\text { Birth weight } \\
\text { SGA }\end{array}$ \\
\hline Choi et al..$^{(34)}$ & South Korea & Prospective cohort & 220 & $\begin{array}{l}\text { First trim: } 22.3 \% \\
\text { Second: } 37.7 \% \\
\text { Third: } 40.0 \%\end{array}$ & 5.9 & LC-MS & $<50 v . \geq 50$ & SGA \\
\hline Crozier et al. ${ }^{(15)}$ & UK & Prospective cohort & $\begin{array}{l}\text { At birth: } 574 \\
\text { At 4: } 565 \\
\text { At } 6: 447\end{array}$ & 34.0 & NA & RIA & $<50 v . \geq 50$ & $\begin{array}{l}\text { Fat mass at birth, at ages } 4 \text { years } \\
\text { and } 6 \text { years }\end{array}$ \\
\hline Dalgard et al. ${ }^{(35)}$ & Denmark & Prospective cohort & 1038 & Cord blood & NA & LC-MS & $<25 v \cdot \geq 25$ & $\begin{array}{l}\text { Birth weight } \\
\text { Newborn length } \\
\text { Newborn head circumference }\end{array}$ \\
\hline Eckhardt et al. ${ }^{(36)}$ & USA & Retrospective cohort & 2473 & $20 \cdot 7(15,9 ; 23,4)$ & $23 \cdot 0$ & LC-MS & $<30 v . \geq 30$ & $\begin{array}{l}\text { Newborn head circumference } \\
\text { Birth weight } \\
\text { Newborn length } \\
\text { Newborn head circumference } \\
\text { Weight } z \text { score, length } z \text {-score, head } \\
\text { circumference } z \text {-score at age } 1 \text { year }\end{array}$ \\
\hline $\begin{array}{l}\text { Fernandez-Alonso } \\
\text { et al. }{ }^{(37)}\end{array}$ & Spain & Cross-sectional & 466 & First trimester & NA & ECLI & $<50 v . \geq 50$ & SGA \\
\hline Gale et al. ${ }^{(16)}$ & UK & Prospective cohort & $\begin{array}{l}\text { Birth: } 466 \\
\text { At } 9 \text { months: } 440 \\
\text { At } 9 \text { years: } 178\end{array}$ & $\begin{array}{l}28 \cdot 0-42 \cdot 0 \\
\text { Median: } 32 \cdot 6\end{array}$ & NA & RIA & $\begin{array}{l}<30 v \cdot \geq 30 \\
<50 v \cdot \geq 50\end{array}$ & $\begin{array}{l}\text { Birth weight } \\
\text { Newborn length } \\
\text { Newborn head circumference } \\
\text { Length and weight at age } 9 \text { months } \\
\text { Fat mass, BMI, height at age } 9 \text { years }\end{array}$ \\
\hline $\begin{array}{l}\text { Gernand et al.38) } \\
\text { Gernand et al. }\end{array}$ & $\begin{array}{l}\text { US } \\
\text { USA }\end{array}$ & $\begin{array}{l}\text { Retrospective cohort } \\
\text { Prospective cohort }\end{array}$ & $\begin{array}{l}2146 \\
792\end{array}$ & $\begin{array}{c}20 \cdot 6(15 \cdot 7,23 \cdot 4) \\
\leq 26 \cdot 0\end{array}$ & $\begin{array}{l}23 \cdot 9 \\
23 \cdot 5\end{array}$ & $\begin{array}{l}\text { LC-MS } \\
\text { LC-MS }\end{array}$ & $\begin{array}{l}<37.5 v_{.} \geq 37.5 \\
<50 v_{.} \geq 50\end{array}$ & $\begin{array}{l}\text { SGA } \\
\text { SGA }\end{array}$ \\
\hline Gould et al. ${ }^{(40)}$ & Australia & Prospective cohort & $316 / 318$ & Cord blood & NA & LC-MS & $<25$ v. $\geq 25$ & $\begin{array}{l}\text { Weight z-score, length z-score, head } \\
\text { circumference z-score at age } 1 \text { year }\end{array}$ \\
\hline Josefson et al..$^{(17)}$ & USA & Prospective cohort & 340 & Cord blood & $50 \cdot 3$ & HPLC-MS & $<50 v . \geq 50$ & $\begin{array}{l}\text { Birth weight } \\
\text { Neonatal body fat (\%) } \\
\text { Newborn length }\end{array}$ \\
\hline $\begin{array}{l}\text { Krishnaveni } \\
\text { et al. }{ }^{(41)}\end{array}$ & India & Prospective cohort & $505 / 469$ & $28 \cdot 0-32 \cdot 0$ & NA & RIA & $<50 v . \geq 50$ & $\begin{array}{l}\text { Fat mass, BMl, height at age } 9 \text { years } \\
\text { Fat mass at age } 5 \text { years }\end{array}$ \\
\hline Leffelaar et al. ${ }^{(18)}$ & Netherlands & Prospective cohort & 3730 & $13 \cdot 5$ (sD 3.3) & 43.6 summer & ELISA & $<50 v . \geq 50$ & $\begin{array}{l}\text { SGA } \\
\text { Birth weight } \\
\text { Length and weight at age } 9 \text { months }\end{array}$ \\
\hline $\begin{array}{l}\text { Miettinen et al.(42) } \\
\text { Morgan et al. }{ }^{(43)}\end{array}$ & $\begin{array}{l}\text { Finland } \\
\text { Canada }\end{array}$ & $\begin{array}{l}\text { Retrospective cohort } \\
\text { Nested case-control }\end{array}$ & $\begin{array}{c}686 \\
1328 \\
\text { (cases: } 301 \text { ) }\end{array}$ & $\begin{array}{l}\text { First trimester } \\
\text { Cord blood }\end{array}$ & $\begin{array}{l}\text { NA } \\
\text { NA }\end{array}$ & $\begin{array}{l}\text { ELISA } \\
\text { CLIA }\end{array}$ & $\begin{array}{l}<50 \text { v. } \geq 50 \\
<50 \text { v. } \geq 50\end{array}$ & $\begin{array}{l}\text { Diabetes type I } \\
\text { SGA }\end{array}$ \\
\hline Morley et al. ${ }^{(44)}$ & Australia & Prospective cohort & 374 & $28 \cdot 0-32 \cdot 0$ & NA & RIA & $<28 v . \geq 28$ & $\begin{array}{l}\text { Birth weight } \\
\text { Newborn head circumference } \\
\text { Newborn length }\end{array}$ \\
\hline Ong et al.. .45$)$ & Singapore & Prospective cohort & 910 & $26 \cdot 8$ & $\begin{array}{l}\text { Tropical rainforest } \\
\text { climate all year long }\end{array}$ & LC-MS & $<50 v . \geq 50$ & $\begin{array}{l}\text { Birth weight } \\
\text { Newborn length } \\
\text { SGA }\end{array}$ \\
\hline $\begin{array}{l}\text { Reichetzeder } \\
\text { et al. }{ }^{(46)}\end{array}$ & Germany & Prospective cohort & 547 & NA & NA & ELISA & $<25 v \cdot \geq 25$ & $\begin{array}{l}\text { Birth weight } \\
\text { Newborn length }\end{array}$ \\
\hline Rodriguez et al. ${ }^{(47)}$ & Spain & Prospective cohort & 2342 & $13.5(2 \cdot 2)$ & $\begin{array}{c}\leq 54.5 \mathrm{nmol} / /: 36 \cdot 2 \\
54.5-73.5 \mathrm{nmol} / \mathrm{l}: 24.5 \\
73.5-93 \mathrm{nmol} / /: 18 \cdot 6 \\
>93 \mathrm{nmol} / \mathrm{l}: 15 \cdot 5\end{array}$ & HPLC & $<50$ v. $\geq 50$ & $\begin{array}{l}\text { Newborn head circumterence } \\
\text { SGA }\end{array}$ \\
\hline
\end{tabular}


prenatal vitamin D status and newborn head circumference was found (MD $-0.11 ; 95 \% \mathrm{CI}-0.30,0.09 ; P=0.27$ ). There was significant heterogeneity $\left(\tau^{2}=0.04 ; \chi^{2}=17 \cdot 37 ; I^{2}=65 \% ; P=0.008\right)$.

The association between prenatal vitamin D status and risk of SGA is presented in Fig. 3. There were a total of sixteen studies $^{(18,28,29,31-34,37-39,43,45,47,48,52,53) \quad \text { involving } 26292}$ patients. Vitamin D deficiency was defined using circulating $25(\mathrm{OH}) \mathrm{D}$ level of $50 \mathrm{nmol} / \mathrm{l}$ as the cut-off in eight studies $^{(33,34,37,43,45,47,52,53)}, 37 \cdot 5 \mathrm{nmol} / 1$ in two studies ${ }^{(29,38)}$, $30 \mathrm{nmol} / \mathrm{l}^{(18,39)}$ in two studies and of $25 \mathrm{nmol} / 1$ in four studies $^{(28,31,32,48)}$. Vitamin D deficiency was associated with an increased risk of SGA with an overall OR of 1.55 (95\% CI $1 \cdot 16$, $2 \cdot 07)(P=0 \cdot 003)$. There was significant heterogeneity $\left(\tau^{2}=0 \cdot 26\right.$; $\left.\chi^{2}=102 \cdot 22 ; I^{2}=85 \%, P<0 \cdot 00001\right)$.

Two studies ${ }^{(16,18)}$ involving 4170 infants reported the association between prenatal vitamin D status and infant growth at the age of 9 months (Fig. 4). Compared with prenatal adequate vitamin D levels, infants with low prenatal vitamin D status had heavier weight (g) (MD 119.75; 95\% CI 32.97, 206.52; $P=0.007)$. There was no association between prenatal vitamin D status and length $(\mathrm{cm})$ at 9 months (MD $-0.09 ; 95 \%$ CI $-0.30,0.13 ; P=0.43)$. No significant heterogeneity was detected across studies.

Two studies ${ }^{(36,40)}$ examined the relationship between prenatal vitamin D status and infant growth at the age of 1 year, including weight-for-age $z$ score, length-for-age $z$ score and head-circumference-for-age $z$ score. The sample size was 2791 for length and head circumference, and 2789 for weight. Prenatal vitamin $\mathrm{D}$ deficiency was associated with lower headcircumference-for-age $z$ score at the age of 1 year (MD $-0 \cdot 27$; $95 \%$ CI $-0.37,-0 \cdot 17 ; P<0.00001)$. There was no significant association between prenatal vitamin $\mathrm{D}$ status and weight-forage $z$ score (MD $-0.09 ; 95 \%$ CI $-0.18,0.01 ; P=0.06$ ) or the length-for-age $z$ score (MD $-0 \cdot 05 ; 95 \% \mathrm{CI}-0 \cdot 38,0 \cdot 27 ; P=0 \cdot 75$ ). The heterogeneity is significant for length-for-age $\left(\tau^{2}=0 \cdot 04\right.$; $\left.\chi^{2}=3 \cdot 23 ; I^{2}=69 \% ; P=0 \cdot 07\right)$, whereas there was no significant heterogeneity for weight-for-age $z$ score or headcircumference-for-age $z$ score.

Two studies ${ }^{(15,41)}$ examined maternal vitamin D status in pregnancy and adiposity in the offspring at birth and 4-6 years of age. Krishnaveni et al. ${ }^{(41)}$ measured fat mass at the age of 5 years and Crozier et al. measured fat mass at birth and at ages 4 and 6 years. Crozier et $a l^{(15)}$ reported that low maternal vitamin D status was associated with lower fat mass at birth and higher fat mass at the age of 6 years. No significant association was found at the age of $4^{(15)}$ or 5 years ${ }^{(41)}$. The data could not be pooled as adiposity was not measured at the same age.

Two studies, Gale 2008 ${ }^{(16)}$ and Krishnaveni $2011^{(41)}$, compared height, BMI and fat mass at the age of 9 years according to prenatal vitamin D status (deficiency $v$. non-deficiency). The total sample size for these three measures was 647 . There were no associations between prenatal vitamin D status and height, BMI and fat mass at 9 years of age. The summary MD were $-0 \cdot 11$ (95\% CI $-1 \cdot 07,0 \cdot 84)(P=0 \cdot 81)$ for height, -0.34 (95\% CI $-0.78,0 \cdot 10)(P=0.13)$ for BMI and -0.40 (95\% CI -1.36 , $0.57)(P=0.42)$ for fat mass. There was no evidence of heterogeneity for height. The heterogeneity was significant for 
Prenatal vitamin D and offspring growth

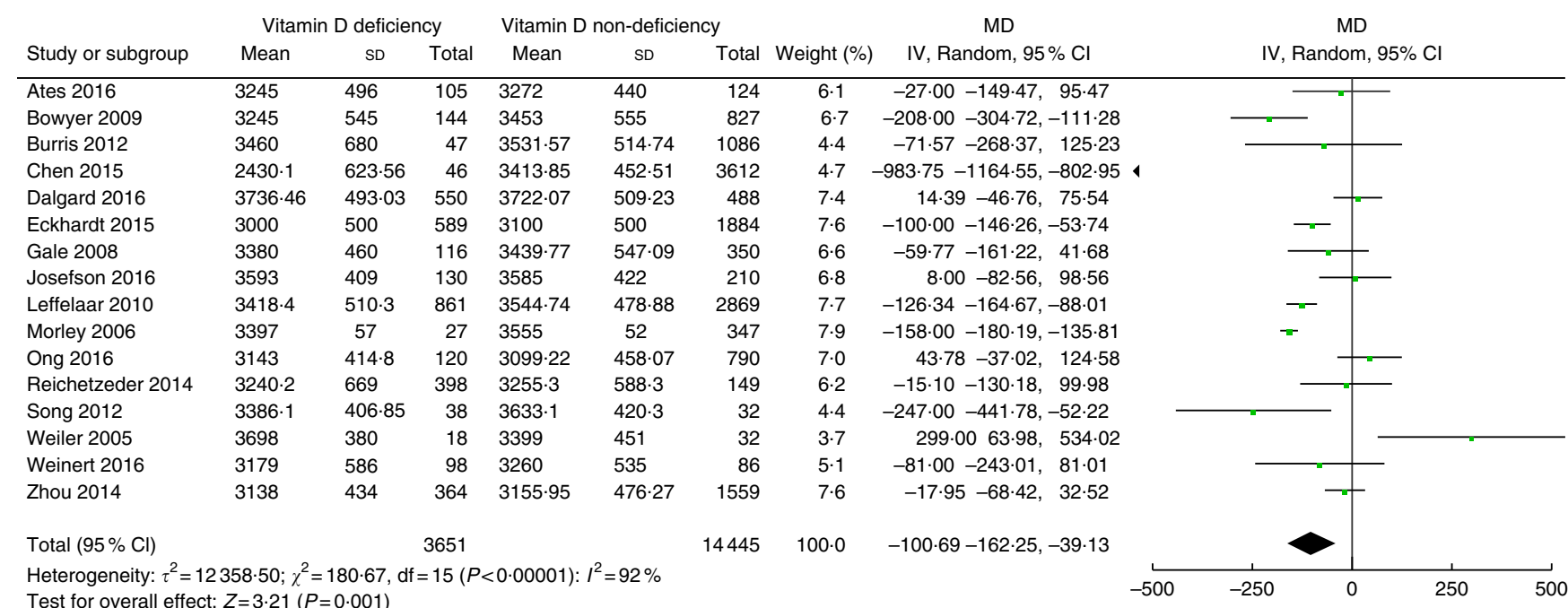

Fig. 2. Forest plots of summary mean difference (MD) (g) of birth weight between prenatal vitamin $D$ deficiency and vitamin $D$ non-deficiency.

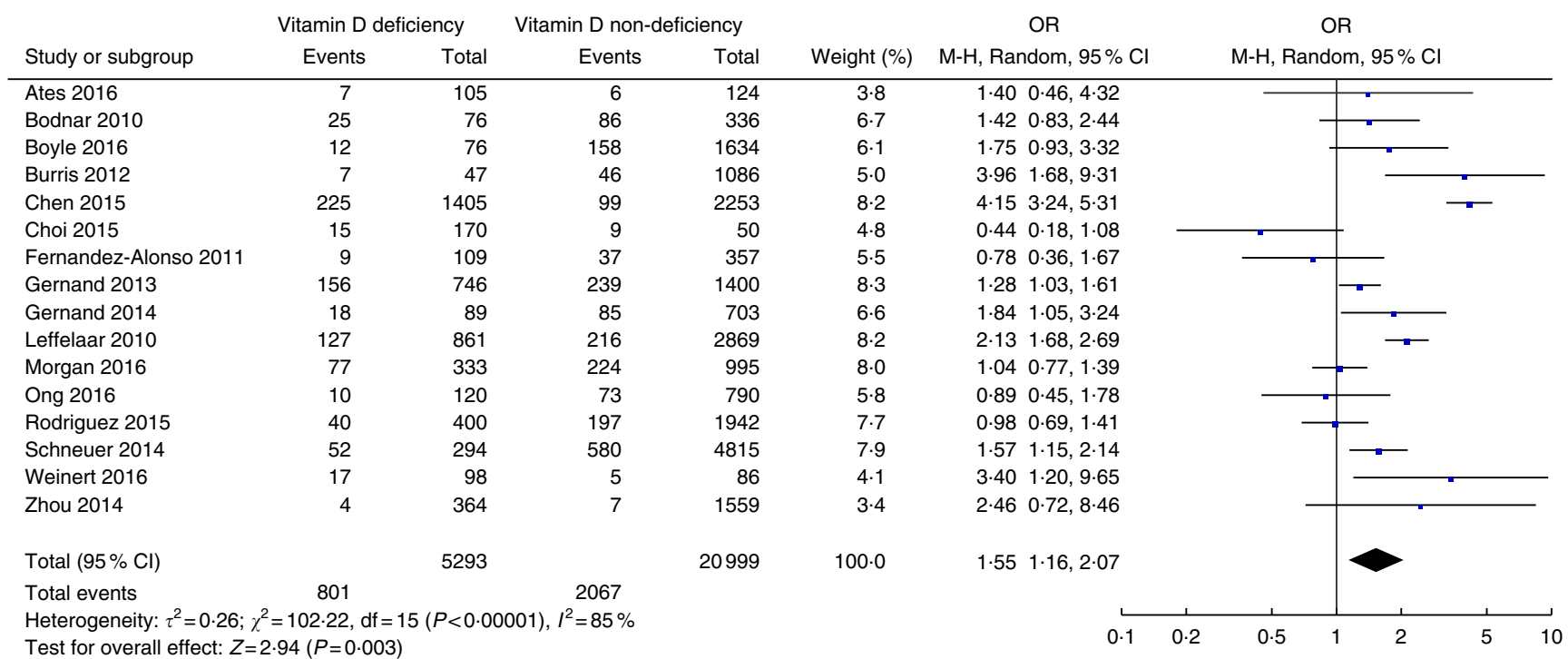

Fig. 3. Forest plots of summary crude OR of the association between prenatal low 25-hydroxyvitamin D levels and small-for-gestational-age.

BMI $\left(\tau^{2}=0.07 ; \quad \chi^{2}=2.92 ; \quad I^{2}=66 \% ; P=0.09\right)$ and fat mass $\left(\tau^{2}=0.41 ; \chi^{2}=7 \cdot 01 ; I^{2}=86 \% ; P=0 \cdot 008\right)$.

The risk of diabetes type 1 in prenatal vitamin D-deficient mother-child pairs has been compared with vitamin D-nondeficient mother-child pairs in two studies ${ }^{(42,50)}$, including 1014 mother-child pairs. Sorensen et al. ${ }^{(50)}$ showed that low maternal $25(\mathrm{OH}) \mathrm{D}$ level was associated with increased risk of diabetes type 1 in children (the mean age at diabetes diagnosis was 9 years), whereas Miettinen et $a l .{ }^{(42)}$ did not observe any difference between 25(OH)D levels of the case and control mothers (the mean age at diabetes diagnosis was 3 years). The meta-analysis results show that low maternal vitamin D status during pregnancy was not associated with risk of diabetes type 1 in the offspring. The summary crude OR was $1.25(95 \%$ CI $0.78,2.02)$. There was significant heterogeneity $\left(\tau^{2}=0.08\right.$; $\left.\chi^{2}=2 \cdot 65 ; I^{2}=62 \% ; P=0 \cdot 10\right)$.

\section{Discussion}

The main findings of this systematic review and meta-analysis was that low prenatal vitamin D status was associated with lower birth weight and increased risk of SGA. Interestingly, low prenatal vitamin D status was associated with greater weight in infants at the age of 9 months, but no significant difference was observed in length, indicating that low prenatal vitamin D status may be linked to accelerated growth and adiposity in early postnatal life. However, prenatal vitamin D deficiency was not related with risk of childhood diabetes type 1.

Previous systematic reviews of observational studies mainly focused on vitamin D during pregnancy and maternal and neonatal outcomes. Aghajafari's meta-analysis found an association between prenatal vitamin D deficiency and lower birth weight and elevated risks of SGA, as well as other maternal 
(a)

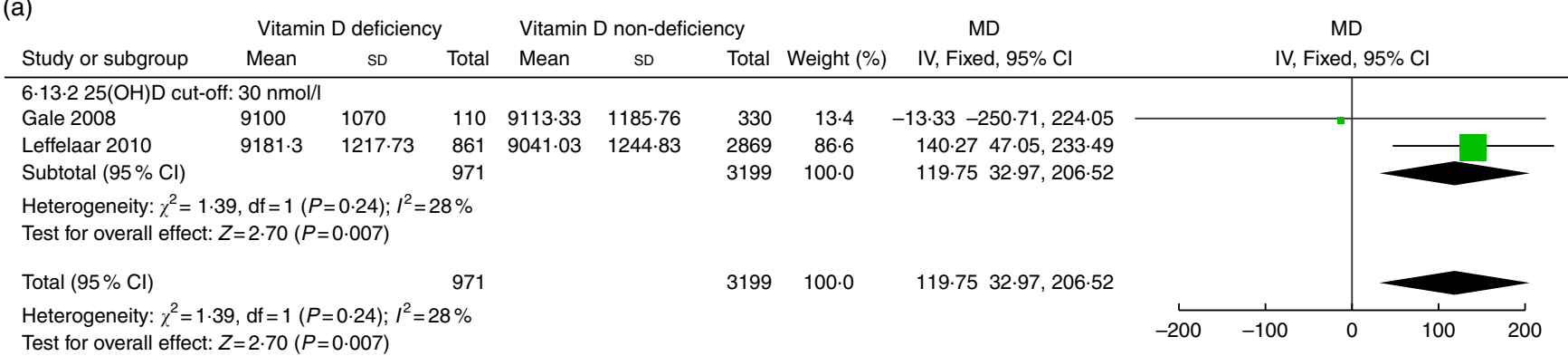

Test for subgroup differences: not applicable

(b)

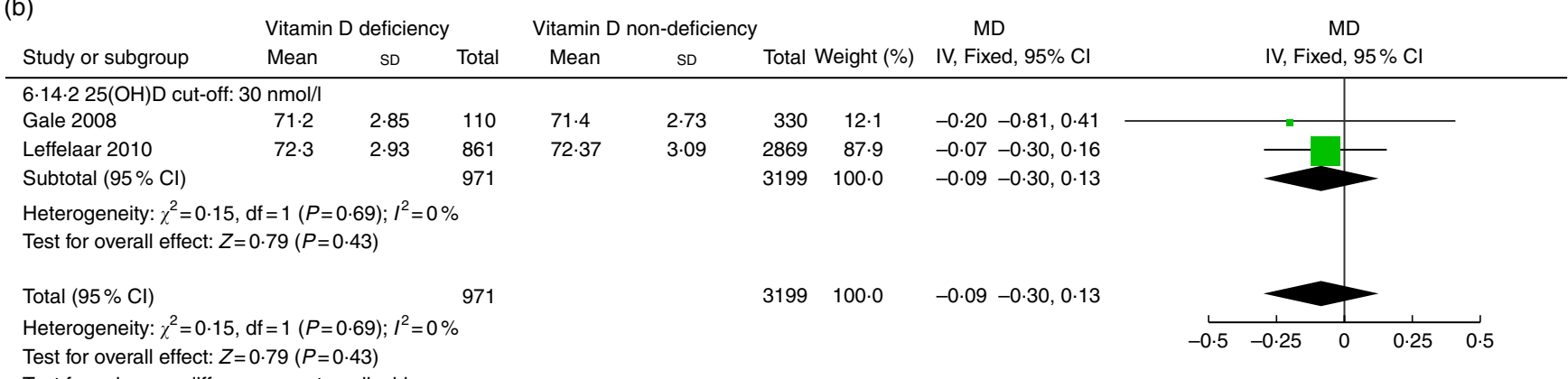

Test for subqroup differences: not applicable

Fig. 4. Forest plots of summary mean difference (MD) of anthropometry in infants at the age of 9 months between prenatal vitamin $D$ deficiency and vitamin D non-deficiency. (a). The association between prenatal vitamin $\mathrm{D}$ deficiency and infant weight ( $\mathrm{g}$ ) at the age of 9 months. (b). The association between prenatal vitamin $\mathrm{D}$ deficiency and infant length $(\mathrm{cm})$ at the age of 9 months. 25(OH)D, 25-hydroxyvitamin $\mathrm{D}$.

outcomes ${ }^{(55)}$. Nassar's review also showed similar results with an increased risk of SGA associated with maternal vitamin D deficiency ${ }^{(56)}$. Our previous systematic review found that maternal low vitamin D status was associated with increased risk of adverse pregnancy outcomes including preeclampsia, gestational diabetes, preterm birth and $\mathrm{SGA}^{(57)}$. The present review focuses on the impact of low prenatal vitamin $D$ status on offspring growth, adiposity and metabolic health in the literature up to 2017/07.

The results of this meta-analysis show that low maternal vitamin D status was associated with higher weight at the age of 9 months, indicating that maternal low vitamin D status may be associated with an accelerated postnatal growth. Accelerated growth during infancy has been reported to be associated with childhood adiposity ${ }^{(58)}$ and the risk of subsequent overweight $^{(58)}$ or obesity ${ }^{(59)}$. However, results have to be interpreted cautiously. The mean weight difference in infants at the age of 9 months was only $119.75 \mathrm{~g}$ ( $1.3 \%$ of infant weight), which may not be clinically relevant. Although there is a lack of data on what percentage of weight difference during infancy can increase odds of overweight or obesity in later life, further research is needed in this area. In addition, confounding factors such as dietary intake and breast-feeding during infancy may have affected this relationship. Adiposity was observed to be elevated at child at age 6 years in prenatally vitamin D-deficient mother-offspring pairs ${ }^{(15)}$.

An association between maternal vitamin D deficiency and risk of diabetes type 1 in children was not observed in this meta-analysis. However, there were only two studies that examined the link between maternal vitamin D status and diabetes in offspring. A nested case-control study ${ }^{(50)}$ showed the association, whereas another study ${ }^{(42)}$ did not. However, the mean age at diagnosis for diabetes was too young (only about 3.4 years) in the Miettinen study ${ }^{(42)}$, whereas the peak incidence for diabetes in children is at age 10-14 years, and thus this study cannot exclude the possibility that maternal vitamin D deficiency may contribute to the risk of diabetes type 1 . More longitudinal cohort studies with longer follow-up of children (age 10-14 years) are needed to clarify this association.

The underlying mechanisms in the association between maternal vitamin D during pregnancy and infant growth and adiposity are biologically plausible. Indeed, vitamin D promotes $\mathrm{Ca}$ and $\mathrm{P}$ absorption, which is essential for the mineralisation process during fetal bone formation ${ }^{(60)}$. During pregnancy, the placenta synthesises vitamin D to help achieve a higher concentration in circulation ${ }^{(12)}$. As Ca reaches fetal circulation by crossing the placental barrier, the mineralisation of fetus bones depends on the mother's Ca absorption. Therefore, vitamin D deficiency in the mother can induce Ca deficiency in the fetus, which may affect bone formation in the fetus ${ }^{(61)}$. In addition, intra-uterine exposure to low vitamin D status negatively affects fetal skeletal muscle ${ }^{(62)}$ and adiposity development ${ }^{(15)}$. The adverse effects of prenatal vitamin D deficiency on fetal bone ${ }^{(61)}$, muscle $^{(62)}$ and fat ${ }^{(15)}$ development might be responsible for lower birth weight or SGA. Vitamin D also helps to reduce inflammatory response during pregnancy and contributes to embryo implantation $^{(12)}$. Moreover, it is widely accepted that vitamin D is mainly stored in adipose tissue ${ }^{(63)}$. Numerous studies have reported a correlation between vitamin D deficiency and obesity ${ }^{(64)}$. However, the causal relationship between vitamin D status and 
obesity remains unclear. Vitamin D deficiency might play a role in the development of obesity because decreased circulating $25(\mathrm{OH}) \mathrm{D}$ levels could result from a modification in vitamin $\mathrm{D}$ metabolism occurring during obesity development ${ }^{(65)}$. Indeed, modifications in the expression of genes encoding key enzymes of vitamin D metabolism have been reported in the adipose tissue of obese people ${ }^{(66)}$. Accelerated postnatal growth may promote adiposity $^{(3)}$ and thus an elevated fat mass. Our finding that prenatally vitamin D-deficient infants had lower weight at birth but heavier weight at 9 months of age is consistent with a recent study from the animal model ${ }^{(67)}$, indicating that prenatal vitamin $\mathrm{D}$ status may affect adiposity in offspring.

Some limitations of this review should be noted. First, there is no universal definition of vitamin $\mathrm{D}$ deficiency, and various definitions were used in individual studies. However, we performed overall analysis based on vitamin D deficiency and non-deficiency, as well as subgroup analysis according to the specific cut-off of $25(\mathrm{OH}) \mathrm{D}$ level, and the findings were similar. Second, the observed associations between prenatal vitamin D status and offspring outcomes could be affected by potential confounding factors. However, most adjusted OR were similar to the crude estimates. Third, the variability in the assay methods for $25(\mathrm{OH}) \mathrm{D}$ may have affected the results. Finally, loss to follow-up may be an issue for cohort studies on child long-term health outcomes.

This systematic review has strengths. It was the first to summarise the evidence on prenatal vitamin D status on offspring growth, adiposity and metabolic health. It included the most recent studies and followed the MOOSE guidelines ${ }^{(20)}$. The quality of the review data in this review depends on the methodological quality of the included studies. Each study was evaluated using the NOS, and only high-quality observational studies were included in the meta-analysis.

The evidence from this systematic review indicates that low prenatal $25(\mathrm{OH}) \mathrm{D}$ status has an impact on fetal growth and low prenatal vitamin D status may be associated with infant adiposity. Further confirmation of these findings in large longitudinal cohorts is warranted. Carefully defined large multi-centre randomised clinical trials of vitamin D supplementation in pregnancy for improving infant growth need to be implemented to better define the risks and benefits. Given the high prevalence of vitamin $\mathrm{D}$ deficiency in pregnant women, the findings could have substantial public health implications.

\section{Acknowledgements}

Dr S. Q. W. was supported by an award from the Fonds de Recherche en Sante du Quebec.

The authors' contributions were as follows - S. Q. W.: designed and supervised the study (conception and design; analysis and interpretation of data; revising and finalising the paper). C. S.: acquisition, analysis and interpretation of data, and writing and revising the paper. W. G. B. acquisition, analysis and interpretation of data, and revising the article. L. L., N. T., P. J., Z.-C. L., F. A. and A. M. N.: revisions for intellectual content of the manuscript. All authors contributed to the interpretation of data and read and approved the submitted manuscript.

The authors declare that there are no conflicts of interest.

\section{Supplementary material}

For supplementary material/s referred to in this article, please visit https://doi.org/10.1017/S0007114517003646

\section{References}

1. Barker DJ (2007) The origins of the developmental origins theory. J Intern Med 261, 412-417.

2. Charles MA, Delpierre C \& Breant B (2016) [Developmental origin of health and adult diseases (DOHaD): evolution of a concept over three decades]. Med Sci (Paris) 32, 15-20.

3. Okada T, Takahashi S, Nagano N, et al. (2015) Early postnatal alteration of body composition in preterm and smallfor-gestational-age infants: implications of catch-up fat. Pediatr Res 77, 136-142.

4. Palacios C \& Gonzalez L (2014) Is vitamin D deficiency a major global public health problem? J Steroid Biochem Mol Biol 144, 138-145.

5. Institute of Medicine Committee to Review Dietary Reference Intakes for Vitamin D and Calcium; Ross AC, Taylor CL, Yaktine AL, et al. (2011) Dietary Reference Intakes for Calcium and Vitamin D. Washington, DC: National Academies Press.

6. Holick MF, Binkley NC, Bischoff-Ferrari HA, et al. (2011) Evaluation, treatment, and prevention of vitamin D deficiency: an Endocrine Society clinical practice guideline. J Clin Endocrinol Metab 96, 1911-1930.

7. Naeem Z (2010) Vitamin D deficiency- an ignored epidemic. Int J Health Sci (Qassim) 4, V-VI.

8. Holick MF \& Chen TC (2008) Vitamin D deficiency: a worldwide problem with health consequences. Am J Clin Nutr 87, 1080S-1086S.

9. Janz T \& Pearson C (2015) Vitamin D Blood Levels of Canadians, Statistics Canada Catalogue no. 82-624-X. Canada: Statistics Canada. https://www.statcan.gc.ca/pub/82-624-x/ 2013001/article/11727-eng.htm (accessed December 2017).

10. Wei SQ, Audibert F, Hidiroglou N, et al. (2012) Longitudinal vitamin $\mathrm{D}$ status in pregnancy and the risk of pre-eclampsia. BJOG 119, 832-839.

11. McAree T, Jacobs B, Manickavasagar T, et al. (2013) Vitamin D deficiency in pregnancy - still a public health issue. Matern Child Nutr 9, 23-30.

12. Shin JS, Choi MY, Longtine MS, et al. (2010) Vitamin D effects on pregnancy and the placenta. Placenta 31, 1027-1034.

13. Palaniswamy S, Williams D, Jarvelin MR, et al. (2015) Vitamin D and the promotion of long-term metabolic health from a programming perspective. Nutr Metab Insights 8, 11-21.

14. Wells $G$ (2014) The Newcastle-Ottawa Scale (NOS) for assessing the quality of nonrandomised studies in meta-analyses. www.ohri.ca/programs/clinical_epidemiology/ oxford.asp (accessed June 2017).

15. Crozier SR, Harvey NC, Inskip HM, et al. (2012) Maternal vitamin $\mathrm{D}$ status in pregnancy is associated with adiposity in the offspring: findings from the Southampton Women's Survey. Am J Clin Nutr 96, 57-63.

16. Gale CR, Robinson SM, Harvey NC, et al. (2008) Maternal vitamin D status during pregnancy and child outcomes. Eur J Clin Nutr 62, 68-77.

17. Josefson JL, Reisetter A, Scholtens DM, et al. (2016) Maternal BMI associations with maternal and cord blood vitamin D Levels in a North American Subset of Hyperglycemia and Adverse Pregnancy Outcome (HAPO) study participants. PLOS ONE 11, e0150221.

18. Leffelaar ER, Vrijkotte TG \& van Eijsden M (2010) Maternal early pregnancy vitamin D status in relation to fetal and neonatal 
growth: results of the multi-ethnic Amsterdam Born Children and their Development cohort. Br J Nutr 104, 108-117.

19. Nordic Cochrane Centre (2014) Review Manager (RevMan) [Computer program], version 5.3. Copenhagen: The Nordic Cochrane Centre, The Cochrane Collaboration. http://community. cochrane.org/tools/review-production-tools/revman-5/aboutrevman-5 (accessed May 2017).

20. Stroup DF, Berlin JA, Morton SC, et al. (2000) Meta-analysis of observational studies in epidemiology: a proposal for reporting. Meta-analysis Of Observational Studies in Epidemiology (MOOSE) group. JAMA 283, 2008-2012.

21. Brekke HK \& Ludvigsson J (2007) Vitamin D supplementation and diabetes-related autoimmunity in the ABIS study. Pediatr Diabetes 8, 11-14.

22. Brough L, Rees GA, Crawford MA, et al. (2010) Effect of multiple-micronutrient supplementation on maternal nutrient status, infant birth weight and gestational age at birth in a lowincome, multi-ethnic population. Br J Nutr 104, 437-445.

23. Hashemipour S, Ziaee A, Javadi A, et al. (2014) Effect of treatment of vitamin D deficiency and insufficiency during pregnancy on fetal growth indices and maternal weight gain: a randomized clinical trial. Eur J Obstet Gynecol Reprod Biol 172, 15-19.

24. Hossain N, Kanani FH, Ramzan S, et al. (2014) Obstetric and neonatal outcomes of maternal vitamin $\mathrm{D}$ supplementation: results of an open-label, randomized controlled trial of antenatal vitamin D supplementation in Pakistani women. J Clin Endocrinol Metab 99, 2448-2455.

25. Kalra P, Das V, Agarwal A, et al. (2012) Effect of vitamin D supplementation during pregnancy on neonatal mineral homeostasis and anthropometry of the newborn and infant. $\mathrm{Br}$ J Nutr 108, 1052-1058.

26. Sablok A, Batra A, Thariani K, et al. (2015) Supplementation of vitamin $\mathrm{D}$ in pregnancy and its correlation with feto-maternal outcome. Clin Endocrinol (Oxf) 83, 536-541.

27. Savvidou MD, Akolekar R, Samaha RB, et al. (2011) Maternal serum 25-hydroxyvitamin D levels at 11(+0)-13(+6) weeks in pregnant women with diabetes mellitus and in those with macrosomic neonates. BJOG 118, 951-955.

28. Ates S, Sevket O, Ozcan P, et al. (2016) Vitamin D status in the first-trimester: effects of Vitamin D deficiency on pregnancy outcomes. Afr Health Sci 16, 36-43.

29. Bodnar LM, Catov JM, Zmuda JM, et al. (2010) Maternal serum 25-hydroxyvitamin D concentrations are associated with small-for-gestational age births in white women. J Nutr 140, 999-1006.

30. Bowyer L, Catling-Paull C, Diamond T, et al. (2009) Vitamin D, PTH and calcium levels in pregnant women and their neonates. Clin Endocrinol (Oxf) 70, 372-377.

31. Boyle VT, Thorstensen EB, Mourath D, et al. (2016) The relationship between 25 -hydroxyvitamin $\mathrm{D}$ concentration in early pregnancy and pregnancy outcomes in a large, prospective cohort. BrJ Nutr 116, 1409-1415.

32. Burris HH, Rifas-Shiman SL, Camargo CA Jr., et al. (2012) Plasma 25-hydroxyvitamin D during pregnancy and small-for-gestational age in black and white infants. Ann Epidemiol 22, 581-586.

33. Chen $\mathrm{YH}, \mathrm{Fu} \mathrm{L}$, Hao JH, et al. (2015) Maternal vitamin D deficiency during pregnancy elevates the risks of small for gestational age and low birth weight infants in Chinese population. J Clin Endocrinol Metab 100, 1912-1919.

34. Choi R, Kim S, Yoo H, et al. (2015) High prevalence of vitamin D deficiency in pregnant Korean women: the first trimester and the winter season as risk factors for vitamin D deficiency. Nutrients 7, 3427-3448.

35. Dalgard C, Petersen MS, Steuerwald U, et al. (2016) Umbilical cord serum 25-hydroxyvitamin D concentrations and relation to birthweight, head circumference and infant length at age 14 days. Paediatr Perinat Epidemiol 30, 238-245.

36. Eckhardt CL, Gernand AD, Roth DE, et al. (2015) Maternal vitamin D status and infant anthropometry in a US multi-centre cohort study. Ann Hum Biol 42, 215-222.

37. Fernandez-Alonso AM, Dionis-Sanchez EC, Chedraui $\mathrm{P}$, et al. (2012) First-trimester maternal serum 25-hydroxyvitamin D(3) status and pregnancy outcome. Int $J$ Gynaecol Obstet 116, 6-9

38. Gernand AD, Simhan HN, Klebanoff MA, et al. (2013) Maternal serum 25-hydroxyvitamin D and measures of newborn and placental weight in a U.S. multicenter cohort study. J Clin Endocrinol Metab 98, 398-404.

39. Gernand AD, Simhan HN, Caritis S, et al. (2014) Maternal vitamin D status and small-for-gestational-age offspring in women at high risk for preeclampsia. Obstet Gynecol 123, 40-48.

40. Gould JF, Anderson AJ, Yelland LN, et al. (2017) Association of cord blood vitamin D with early childhood growth and neurodevelopment. J Paediatr Child Health 53, 75-83.

41. Krishnaveni GV, Veena SR, Winder NR, et al. (2011) Maternal vitamin $\mathrm{D}$ status during pregnancy and body composition and cardiovascular risk markers in Indian children: the Mysore Parthenon Study. Am J Clin Nutr 93, 628-635.

42. Miettinen ME, Reinert L, Kinnunen L, et al. (2012) Serum 25-hydroxyvitamin D level during early pregnancy and type 1 diabetes risk in the offspring. Diabetologia 55, 1291-1294.

43. Morgan C, Dodds L, Langille DB, et al. (2016) Cord blood vitamin D status and neonatal outcomes in a birth cohort in Quebec, Canada. Arch Gynecol Obstet 293, 731-738.

44. Morley R, Carlin JB, Pasco JA, et al. (2006) Maternal 25-hydroxyvitamin $\mathrm{D}$ and parathyroid hormone concentrations and offspring birth size. J Clin Endocrinol Metab 91, 906-912.

45. Ong YL, Quah PL, Tint MT, et al. (2016) The association of maternal vitamin D status with infant birth outcomes, postnatal growth and adiposity in the first 2 years of life in a multiethnic Asian population: the Growing Up in Singapore Towards healthy Outcomes (GUSTO) cohort study. Br J Nutr 116, 621-631.

46. Reichetzeder C, Chen H, Foller M, et al. (2014) Maternal vitamin D deficiency and fetal programming-lessons learned from humans and mice. Kidney Blood Press Res 39, 315-329.

47. Rodriguez A, Garcia-Esteban R, Basterretxea M, et al. (2015) Associations of maternal circulating 25-hydroxyvitamin D3 concentration with pregnancy and birth outcomes. BJOG $\mathbf{1 2 2}$, 1695-1704.

48. Schneuer FJ, Roberts CL, Guilbert C, et al. (2014) Effects of maternal serum 25-hydroxyvitamin D concentrations in the first trimester on subsequent pregnancy outcomes in an Australian population. Am J Clin Nutr 99, 287-295.

49. Song SJ, Si S, Liu J, et al. (2013) Vitamin D status in Chinese pregnant women and their newborns in Beijing and their relationships to birth size. Public Health Nutr 16, 687-692.

50. Sorensen IM, Joner G, Jenum PA, et al. (2012) Maternal serum levels of 25-hydroxy-vitamin D during pregnancy and risk of type 1 diabetes in the offspring. Diabetes 61, 175-178.

51. Weiler H, Fitzpatrick-Wong S, Veitch R, et al. (2005) Vitamin D deficiency and whole-body and femur bone mass relative to weight in healthy newborns. CMAJ 172, 757-761.

52. Weinert LS, Reichelt AJ, Schmitt LR, et al. (2016) Vitamin D deficiency increases the risk of adverse neonatal outcomes in gestational diabetes. PLOS ONE 11, e0164999.

53. Zhou J, Su L, Liu M, et al. (2014) Associations between 25-hydroxyvitamin D levels and pregnancy outcomes: a prospective observational study in southern China. Eur J Clin Nutr 68, 925-930. 
54. Mithal A, Wahl DA, Bonjour JP, et al. (2009) Global vitamin D status and determinants of hypovitaminosis D. Osteoporos Int 20, 1807-1820.

55. Aghajafari F, Nagulesapillai T, Ronksley PE, et al. (2013) Association between maternal serum 25-hydroxyvitamin $\mathrm{D}$ level and pregnancy and neonatal outcomes: systematic review and metaanalysis of observational studies. BMJ 346, f1169.

56. Nassar N, Halligan GH, Roberts CL, et al. (2011) Systematic review of first-trimester vitamin $\mathrm{D}$ normative levels and outcomes of pregnancy. Am J Obstet Gynecol 205, 208 e201-e207.

57. Wei SQ, Qi HP, Luo ZC, et al. (2013) Maternal vitamin D status and adverse pregnancy outcomes: a systematic review and meta-analysis. J Matern Fetal Neonatal Med 26, 889-899.

58. Ong KK, Emmett P, Northstone K, et al. (2009) Infancy weight gain predicts childhood body fat and age at menarche in girls. J Clin Endocrinol Metab 94, 1527-1532.

59. Baird J, Fisher D, Lucas P, et al. (2005) Being big or growing fast: systematic review of size and growth in infancy and later obesity. BMJ 331, 929.

60. DeLuca HF (2014) Triennial growth symposium - vitamin D: bones and beyond. J Anim Sci $\mathbf{9 2}$, 917-929.
61. Viljakainen HT, Saarnio E, Hytinantti T, et al. (2010) Maternal vitamin $\mathrm{D}$ status determines bone variables in the newborn. J Clin Endocrinol Metab 95, 1749-1757.

62. Hines EA, Coffey JD, Starkey CW, et al. (2013) Improvement of maternal vitamin D status with 25-hydroxycholecalciferol positively impacts porcine fetal skeletal muscle development and myoblast activity. J Anim Sci 91, 4116-4122.

63. Abbas MA (2017) Physiological functions of vitamin D in adipose tissue. J Steroid Biochem Mol Biol 165, 369-381.

64. Pereira-Santos M, Costa PR, Assis AM, et al. (2015) Obesity and vitamin D deficiency: a systematic review and metaanalysis. Obes Rev 16, 341-349.

65. Landrier JF, Karkeni E, Marcotorchino J, et al. (2016) Vitamin D modulates adipose tissue biology: possible consequences for obesity? Proc Nutr Soc 75, 38-46.

66. Wamberg L, Christiansen T, Paulsen SK, et al. (2013) Expression of vitamin D-metabolizing enzymes in human adipose tissue - the effect of obesity and diet-induced weight loss. Int J Obes (Lond) 37, 651-657.

67. Belenchia AM, Johnson SA, Ellersieck MR, et al. (2017) In utero vitamin $\mathrm{D}$ deficiency predisposes offspring to long-term adverse adipose tissue effects. J Endocrinol 234, 301-313. 